\title{
Using Cross-Sectional Data to Identify and Quantify the Relative Importance of Factors Associated with and Leading to Food Insecurity
}

\author{
Alison Daly ${ }^{1, *}$, Christina M. Pollard ${ }^{1}{ }^{(}$, Deborah A. Kerr $^{1}{ }^{\circledR}$, Colin W. Binns ${ }^{1}{ }^{\circledR}$, \\ Martin Caraher ${ }^{2}(1)$ and Michael Phillips ${ }^{3}(1)$ \\ 1 Faculty of Health Science, School of Public Health, Curtin University, GPO Box U1987, Perth 6845, \\ Western Australia, Australia; C.Pollard@curtin.edu.au (C.M.P.); D.Kerr@curtin.edu.au (D.A.K.); \\ C.Binns@curtin.edu.au (C.W.B.) \\ 2 Centre for Food Policy, City University of London, Northampton Square, London EC1V 0HB, UK; \\ m.caraher@city.ac.uk \\ 3 Harry Perkins Institute for Medical Research, University of Western Australia, Perth 6009, Western Australia, \\ Australia; michael.phillips@perkins.uwa.edu.au \\ * Correspondence: alison.daly@curtin.edu.au; Tel.: +61-8-9266-9266
}

Received: 10 August 2018; Accepted: 16 November 2018; Published: 22 November 2018

\begin{abstract}
Australian governments routinely monitor population household food insecurity (FI) using a single measure-'running out of food at least once in the previous year'. To better inform public health planning, a synthesis of the determinants and how they influence and modify each other in relation to FI was conducted. The analysis used data from the Health \& Wellbeing Surveillance System cross-sectional dataset. Weighted means and multivariable weighted logistic regression described and modelled factors involved in FI. The analysis showed the direction and strength of the factors and a path diagram was constructed to illustrate these. The results showed that perceived income, independent of actual income was a strong mediator on the path to FI as were obesity, smoking and other indicators of health status. Eating out three or more times a week and eating no vegetables more strongly followed FI than preceded it. The analysis identified a range of factors and demonstrated the complex and interactive nature of them. Further analysis using propensity score weighted methods to control for covariates identified hypothetical causal links for investigation. These results can be used as a proof of concept to assist public health planning.
\end{abstract}

Keywords: food insecurity; monitoring; surveillance; determinants; path diagram

\section{Introduction}

Food security exists "when all people, at all times, have physical, social and economic access to sufficient safe and nutritious food that meets their dietary needs and food preferences for an active and healthy life" [1]. Conversely, food insecurity (FI) is the "limited or uncertain availability of nutritionally adequate and safe foods or the limited or uncertain ability to acquire acceptable food in socially acceptable ways" [2], and is increasing in developed countries [3]. FI is adversely related to diet quality [4-10] and has been associated with the double burden of malnutrition, including undernourishment and obesity [11-13] and additionally it has been associated with poor mental health and socioeconomic disadvantages [14-20].

The complexity and impact of FI has been acknowledged and there is an growing amount of attention being directed to its determinants and how they influence and modify each other, calling for a systemic food system response [21]. FI is a problem of social and economic disadvantage, of which 'running out of food' due to insufficient money is only one component [22]. The complex nature 
of decisions about food is constrained by both physical access and choice [23], underpinned by the Food and Agricultural Organization's four pillars of availability: Access, utilization, stability and sustainability [24-26]. There is growing consensus regarding the need to focus on and better integrate social and structural factors when developing policies and interventions to improve public health in high income countries $[27,28]$. Evidence that is accessible to policy makers in the increasingly interrelated and complicated health policy area requires new approaches to research types and analyses [29].

The prevalence of FI in Australia, based on a 2001 review of the literature, showed that the rates were higher among the following groups: Families living with low or unstable incomes, those in remote areas, Aboriginal and Torres Strait Islander people, the unemployed, those living in rental households, single parents, those who were never married, separated or divorced, young adults and the elderly, asylum seekers and migrants, and people with disabilities [30]. FI directly impacts short and long-term health status, contributing to poor physical and psychological health outcomes and Australian health care costs [30]. The paradoxical relationship between FI and obesity has also been demonstrated, also significantly contributing to increasing health care costs [31-34].

Governments are increasingly encouraged to monitor FI, its determinants, mitigating actions, and their effectiveness [35]. Some countries, including Australia, do measure and report the prevalence of FI, including its severity and/or its determinants [36-39], but not routinely. While FI measures are continuously being evaluated and validated to come up with more accurate estimates of FI, the evaluation of the measures generally only contain limited references to determinants [5,40-42]. The severity of FI's effects, as well as its determinants and associated factors are important information used to inform public health planning. Currently there is little recognition among health or social services policy makers regarding the extent of the problem among some population sub-groups, nor the impact of sociodemographic determinants.

This study uses a cross-sectional self-reported dataset (the Western Australian Department of Health's Health \& Wellbeing Surveillance System 2009-2013, (HWSS)) to construct a path diagram of variables leading to 'running out of food' at least once in the previous year because of insufficient money. The analysis evaluates the relative importance of variables associated with FI. Specifically, the study aims to: Conduct an analysis to evaluate the relative importance of a range of associated variables with FI; use the results of the analysis to construct a path diagram to FI; propose hypothetical causal paths to and from FI; and suggest how future research and policy can be developed more effectively.

\section{Materials and Methods}

\subsection{Sample and Measures}

The HWSS cross-sectional computer-assisted telephone interview survey has measured health and wellbeing indicators (including risk factors) since 2002. Stratified samples by area were drawn from the statewide telephone book Electronic White Pages with geocoded addresses. The average participation rate was $90.2 \%$. The 2009 to 2013 dataset, with a total of 21,710 adults aged 18-64 years was analysed. Data were pooled and weighted for probability of selection using iterative proportional fitting with marginal totals for the distribution of Western Australia (WA) residents in 2011 by age, sex and geographic area. The Department of Health in Western Australia datasets are not publicly available. The HWSS was granted ethics approval from the Western Australia Department of Human Research Ethics Committee (HREC 2011/65).

The sociodemographic variables used in this study were: Age, gender, highest level of education attained, living arrangements, area of residence, annual household income (AUD\$), perceived discretional income, country of birth employment status and the geographic area based index that reflects socioeconomic advantage and disadvantage (SEIFA) [43]. Self-reported body weight and height, using a correction for over-reported height and under-reported weight [44], was used to estimate the Body Mass Index (BMI) of each respondent. Health-related variables included the self-assessment 
of: General health, comparison of health with a year prior, psychological distress (using the Kessler 10 index) [45], health risk factors and whether or not the respondent had these variables diagnosed by a doctor. The indicators of self-reported dietary behaviour included daily fruit, vegetable, and low-fat milk intake, as well as weekly take-away food consumption.

\subsection{Analysis}

The strategy adopted for this analysis was to develop a path diagram to describe a hypothetical model for the network of associations that describe running out of food and its consequences. This method has been used previously [46]. Usually this approach would use a structural equation model (SEM) but the outcome (running out of food or not) was dichotomous, meaning that SEM could not be used. Logistic regression analyses were conducted with a reference group of respondents who did not run out of food. The variables listed in Table 1 were statistically significant at $p \leq 0.1$ and were entered into weighted multivariable logistic regression analyses. While some variables were collected as continuous (e.g., age, K10, fruit, vegetables and physical activity estimates) values, we grouped them based upon accepted guidelines for Australian adults where possible. This was done to avoid assumptions of linearity. Both two way and three way interaction terms between the variables were tested on the final multivariable regression models. Bootstrapping (100 repetitions) produced final model estimates with robust measures used to estimate standard errors for the regression analyses. Results at $p<0.05$ were considered to be statistically significant and kept in the model. Goodness of fit was assessed using the Hosmer-Lemeshow test. Diagnostic post-estimation tests, including tests for multicollinearity were conducted. The regression results were used to conduct a path diagram where the Bayesian Information Criteria (BIC) [47] was used to determine whether or not an association preceded or came after 'running out of food'. The ordering with the lowest BIC was used to determine the direction of the association. A difference in BIC of 10 or more (considered a very strong indicator) was the minimum value when deciding upon direction of effect. This corresponded to a $p$ value of $<0.0004$ [48]. The multivariable model was modified to incorporate this information and the path diagram was constructed to reflect the results of the final model. Propensity scores were used to control for potential confounding from the covariates in iterative propensity score weighted logistic regression analyses for four variables. The four variables tested were income, discretional income, eating fast food three or more times a week and eating no vegetables. These four independent variables were operationally defined as variables in the path leading to the outcome of either 'running out of food' or not [49]. Each of these variables were tested for hypothetical causality. All analysis was conducted using Stata 13.1 [50].

\section{Results}

A total of 709 respondents reported 'running out of food' at least once in the previous twelve months and couldn't afford more (unweighted prevalence $=3.3 \%$; weighted prevalence $=4.0 \%$ ). The prevalence of variables associated with running out of food at $p<0.1$ are shown in Table 1 . The table presents both the unweighted and weighted prevalences with $95 \%$ confidence limits and $p$ values for 'running out of food'. A total of 17,682 correspondents had information for all the variables on Table 1 and this was the sample used to run the multivariable weighted logistic regressions.

Table 2 presents the primary multivariable weighted logistic regression that was used as a basis to create the path analysis. The odds ratios for interaction terms that are presented in the path are estimates based on the results of the regression which either attenuates the effect or enhances the effect. This model showed good fit with the data $\left(\chi^{2}=11.02, p=0.27\right)$ and was used as the basis of the path diagram. 
Table 1. The unweighted and weighted prevalences of 'running out of food' by sample characteristics, HWSS 2009-2013 (n= 21,705 a).

\begin{tabular}{|c|c|c|c|c|}
\hline Demographic Variables & Unwght \% & Wght \% & $95 \%$ CI & $p$ \\
\hline $18-24$ & 7.8 & 8.0 & {$[6.5,9.9]$} & \\
\hline $25-34$ & 5.1 & 4.9 & {$[3.8,6.2]$} & \\
\hline $35-44$ & 3.6 & 3.2 & {$[2.6,4.0]$} & \\
\hline $45-54$ & 2.8 & 2.4 & {$[1.9,2.9]$} & \\
\hline $55-64$ & 2.0 & 1.6 & {$[1.3,2.0]$} & $<0.0001$ \\
\hline Tertiary education & 1.4 & 1.9 & {$[1.3,2.6]$} & \\
\hline Less than tertiary education & 3.8 & 4.7 & {$[4.1,5.3]$} & $<0.0001$ \\
\hline Employed & 2.2 & 2.9 & {$[2.5,3.4]$} & \\
\hline Unemployed & 11.4 & 12.6 & {$[9.0,17.7]$} & \\
\hline Home duties & 4.3 & 5.2 & {$[4.0,6.7]$} & \\
\hline Retired & 2.3 & 2.0 & {$[1.3,3.0]$} & \\
\hline Student & 7.5 & 7.1 & {$[4.8,10.3]$} & \\
\hline Unable to work & 17.3 & 17.6 & {$[13.2,23.0]$} & $<0.0001$ \\
\hline Annual household income: over AUD \$40,000 & 1.7 & 2.4 & {$[2.0,2.9]$} & \\
\hline Annual household income: AUD $\$ 20,001-\$ 40,000$ & 7.0 & 9.6 & {$[7.6,12.2]$} & \\
\hline Annual household income: up to AUD $\$ 20,000$ & 15.0 & 17.8 & {$[14.2,22.2]$} & $<0.0001$ \\
\hline Spend left over money or save some per pay & 1.1 & 1.7 & {$[1.4,2.0]$} & \\
\hline Just enough money to get by per pay & 10.6 & 12.5 & {$[10.7,14.5]$} & \\
\hline Not enough money to get by per pay & 17.5 & 19.0 & {$[15.1,23.6]$} & $<0.0001$ \\
\hline Not aboriginal & 3.1 & 3.8 & {$[3.4,4.2]$} & \\
\hline Aboriginal & 12.5 & 15.0 & {$[9.8,22.1]$} & $<0.0001$ \\
\hline Adults living with others & 2.8 & 3.7 & {$[3.3,4.2]$} & \\
\hline Adults living alone & 6.0 & 6.4 & {$[5.2,7.8]$} & $<0.0001$ \\
\hline Born outside Australia & 2.8 & 2.9 & {$[2.3,3.7]$} & \\
\hline Born in Australia & 3.5 & 4.4 & {$[3.9,5.0]$} & 0.002 \\
\hline Rents or pays mortgage & 4.1 & 4.6 & {$[4.3,5.0]$} & \\
\hline No mortgage or Government subsidized housing & 2.5 & 3.1 & {$[2.7,3.4]$} & 0.0003 \\
\hline SEIFA ${ }^{\mathrm{b}}$ Quintile 5 (least disadvantaged area) & 2.4 & 2.9 & {$[2.3,3.6]$} & \\
\hline SEIFA Quintiles 3,4 (less disadvantaged areas) & 3.4 & 4.5 & {$[3.9,5.3]$} & \\
\hline SEIFA Quintiles 1,2 (most disadvantages areas) & 4.0 & 5.2 & {$[4.2,6.4]$} & $<0.0001$ \\
\hline Has a health care card & 10.3 & 11.3 & {$[9.7,13.2]$} & $<0.0001$ \\
\hline Doesn't have private health insurance & 7.0 & 8.3 & {$[7.2,9.6]$} & $<0.0001$ \\
\hline Has asthma & 5.7 & 6.3 & {$[4.7,8.4]$} & 0.0011 \\
\hline Some cardiovascular condition & 5.8 & 7.4 & {$[4.9,11.0]$} & 0.0022 \\
\hline Has cancer & 4.5 & 7.0 & {$[4.3,11.3]$} & 0.0167 \\
\hline Current mental health (depression/anxiety/other) & 9.1 & 9.7 & {$[8.3,11.4]$} & $<0.0001$ \\
\hline Health rated as fair/poor & 8.8 & 8.9 & {$[7.2,11.0]$} & $<0.0001$ \\
\hline Always or often feel a lack of control over health & 12.8 & 13.9 & {$[11.0,17.3]$} & $<0.0001$ \\
\hline Health rated worse than 12 months ago & 7.3 & 9.4 & {$[7.6,11.6]$} & $<0.0001$ \\
\hline High/very high Kessler 10 score & 14.1 & 14.8 & {$[12.4,17.6]$} & $<0.0001$ \\
\hline BMI 30 or more (in obese range) & 4.3 & 5.2 & {$[4.4,6.1]$} & $<0.0012$ \\
\hline Currently smoking & 7.1 & 8.5 & {$[7.0,10.3]$} & $<0.0001$ \\
\hline Does no leisure time physical activity & 4.4 & 5.5 & {$[4.0,7.5]$} & 0.0447 \\
\hline Spends four or more hours sitting in leisure time & 6.4 & 7.6 & {$[5.8,9.8]$} & $<0.0001$ \\
\hline Eats 'fast food' c three or more times a week & 9.1 & 11.9 & {$[8.3,17.0]$} & $<0.0001$ \\
\hline Uses full fat milk & 4.6 & 5.7 & {$[4.9,6.7]$} & $<0.0001$ \\
\hline Doesn't eat any fruit & 6.3 & 6.4 & {$[4.5,9.1]$} & \\
\hline Eats less than two serves of fruit daily & 3.4 & 4.2 & {$[3.6,4.9]$} & \\
\hline Eats two or more serves of fruit daily & 2.7 & 3.3 & {$[2.8,4.0]$} & 0.0030 \\
\hline Doesn't eat any vegetables & 15.0 & 14.9 & {$[6.5,30.4]$} & \\
\hline Eats less than five serves daily & 3.3 & 4.0 & {$[3.6,4.5]$} & \\
\hline Eats five or more serves daily & 2.3 & 2.6 & {$[1.7,3.9]$} & $<0.0012$ \\
\hline
\end{tabular}

\footnotetext{
a Sample with no missing values for each sociodemographic variable: Age $(\mathrm{n}=21,705)$; education $(\mathrm{n}=21,659)$; employment status $(21,556)$; income $(n=17,964)$; perceived spending power $(n=20,959)$; aboriginal or not $(n=21,694)$; born in Australia or not $(n=21,704)$; living arrangements $(n=21,687)$; own or mortgage/rent $(n=21,705)$ SEIFA $(n=21,705) ;{ }^{b}$ SEIFA is an index of relative social disadvantage by area of residence [43] usually presented as quintiles which have been grouped into three levels of social disadvantage for this study; ${ }^{\mathrm{C}}$ Fast food is operationally defined as take away food such as burgers, pizza, chicken or chips from places like McDonalds, Hungry Jacks, Pizza Hut or Red Rooster.
} 
Table 2. Weighted multivariable logistic regression for associations with running out of food including interaction terms, HWSS 2009-2013 $\left(n=17,638^{a}\right)^{b}$.

\begin{tabular}{|c|c|c|}
\hline Main Effects & Odd Ratio (95\% CI) & $p$ \\
\hline 35 over & Ref & \\
\hline 18-34 years & $5.29(3.65,7.65)$ & 0.000 \\
\hline Has tertiary education & Ref & \\
\hline Does not have tertiary education & $1.87(1.38,2.54)$ & 0.000 \\
\hline Not Aboriginal & Ref & \\
\hline Aboriginal & $2.07(1.34,3.2)$ & 0.001 \\
\hline Household income over $\$ 40,000$ & Ref & \\
\hline Household income $\$ 20,000$ to $\$ 40,000$ & $1.65(1.29,2.1)$ & 0.000 \\
\hline Household income under $\$ 20,000$ & $5.28(3.91,7.13)$ & 0.000 \\
\hline Can save a bit of money & Ref & \\
\hline Just enough money to get by & $1.08(0.69,1.71)$ & 0.730 \\
\hline Not enough money to get by & $3.11(2.17,4.46)$ & 0.000 \\
\hline Has private health insurance & Ref & \\
\hline Has no private health insurance & $1.80(1.46,2.22)$ & 0.000 \\
\hline Does not have doctor diagnosed mental health problem & Ref & \\
\hline Has a doctor diagnosed mental health problem & $2.56(1.96,3.35)$ & 0.000 \\
\hline Low or moderate Kessler 10 score & Ref & \\
\hline High or very high Kessler 10 score & $1.65(1.31,2.06)$ & 0.000 \\
\hline Health same or better than same time previous year & Ref & \\
\hline Health worse or much worse than same time previous year & $1.70(1.37,2.09)$ & 0.000 \\
\hline Does not smoke & Ref & \\
\hline Smokes & $1.58(1.29,1.93)$ & 0.000 \\
\hline Is not in Body Mass Index obese range & Ref & \\
\hline Is in Body Mass Index obese range & $1.44(1.18,1.76)$ & 0.000 \\
\hline Eats some vegetables daily & Ref & \\
\hline Eats no vegetables daily & $2.40(1.34,4.3)$ & 0.003 \\
\hline Eats fast foods less than three times a week & Ref & \\
\hline Eats fast foods three or more times a week & $1.83(1.11,3.01)$ & 0.018 \\
\hline Interaction terms & & \\
\hline Has just enough money to get by ${ }^{\#}$ age $18-24$ years & $0.56(0.35,0.91)$ & 0.019 \\
\hline Has a mental health problem ${ }^{\#}$ age $18-24$ years & $0.52(0.31,0.86)$ & 0.010 \\
\hline $\begin{array}{l}\text { Housing whether or not owned or rented \# Not enough or just enough money to } \\
\text { get by }\end{array}$ & $3.35(2.41,4.65)$ & 0.000 \\
\hline Household income under $\$ 20,000$ \# Not enough or just enough money to get by & $3.05(1.94,4.80)$ & 0.000 \\
\hline
\end{tabular}

${ }^{a}$ Logistic reduced the estimation sample as it ran with post stratification adjustment (accounting for new weighted estimation sample); ${ }^{b}$ This is the basic model used to determine the direction of effect. Two further models were then produced: One for associations preceding running out of food and one for associations following running out of food. The odd ratios in the path diagram were taken from these two models; " Denotes interaction terms between variables: Odds ratios less than 1 attenuate the effect and odds ratios greater than 1 enhance the effect.

The path to 'running out of food' and the associations between variables are shown in Figure 1. The path diagram shows both the main effects and the interaction terms that directly or indirectly influence the primary outcome of 'running out of food'. The models showed a good fit with the data, both for the variables that are associated with 'running out of food' $\left(\chi^{2}=12.75 ; p=0.17\right)$ and the possible consequences of 'running out of food' (fast food consumption $\chi^{2}=5.48 ; p=0.71$; not eating vegetables $\chi^{2}=8.82 ; p=0.31$ ).

In Figure 1, the red box represents the outcome measure, demonstrating food insecurity, i.e., 'running out of food' at least once in the previous twelve months. The blue boxes represent sociodemographics that are not able to be changed or are not easily changed. The yellow boxes represent associations which modify other variables on the path to food insecurity as well as being directly associated with food insecurity. The grey boxes represent the hypothesised consequences of food insecurity as informed by the BIC analysis. 


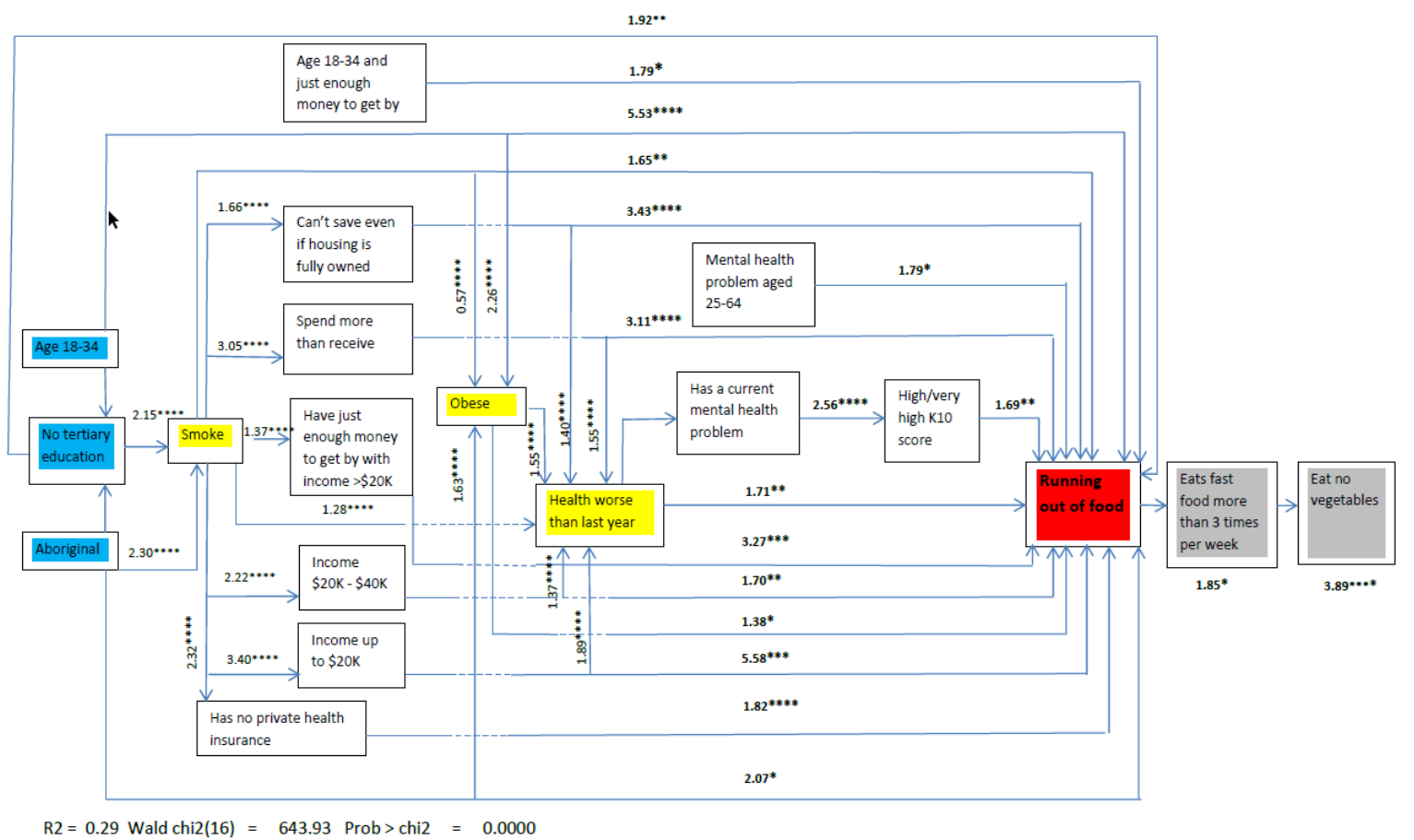

Figure 1. Estimate of probability of eating fast food more than twice a week and eating no vegetables by 'running out of food', adjusted using propensity scores: Showing probable outcomes of 'running out of food', HWSS 2009-2013. ${ }^{*} p<0.05 ;{ }^{* *} p<0.01{ }^{* * *} p<0.001 ;{ }^{* * * *} p<0.0001$.

\subsection{Direct Associations with Food Insecurity}

Of the variables regarded as fixed, only three were directly associated with food insecurity: Age group (18-34 years compared to 35-64 years, odds ratio $(\mathrm{OR})=5.53, p<0.0001)$, prior education level (no tertiary education compared with tertiary education, $\mathrm{OR}=1.92, p<0.01$ ) and Aboriginality (of Aboriginal or Torres Strait Islander origin compared with not, OR $=2.07, p<0.05$ ). With the exception of two variables (which are dependent on 'running out of food') all other variables predicted FI. The two variables that were dependent on 'running out of food' were frequent fast food consumption, which subsequently predicted eating no vegetables.

\subsection{Effect Modifiers in the Food Insecurity Path}

Three variables acted as powerful effect modifiers in the path, shown in the yellow boxes: Smoking, obesity and the perception of worsening health over time (direct association). The size of the effects is shown on the chart as odds rations. To illustrate: Smoking, which is influenced by Aboriginality $(\mathrm{OR}=2.30, p<0.0001)$ and education ( $\mathrm{OR}=2.15, p<0.0001)$, has a main effect on 'running out of food' $(\mathrm{OR}=1.65, p<0.01)$ and also acts as an effect modifier for perceived spending power and income $(\mathrm{OR}=1.65, p<0.01)$, income (AUD\$20-40K OR = 2.22, $p<0.0001$; up to AUD\$20K OR = 3.40, $p<$ $0.0001)$, private health insurance $(\mathrm{OR}=1.65, p<0.01)$ and worsening health status $(\mathrm{OR}=1.65, p<0.01)$.

Obesity influenced by smoking, where aboriginality and younger age has a main effect $(\mathrm{OR}=1.38$, $p<0.05)$ acts as an effect modifier for worsening health ( $\mathrm{OR}=1.55 p<0.0001)$. Worsening health is influenced by smoking, obesity, low income, discretional income, and money problems, which are defined here as any income perceived to be less than needed. It has a main effect ( $\mathrm{OR}=1.71, p<0.01$ ) and acts as an effect modifier on mental health $(\mathrm{OR}=1.71, p<0.01)$.

Independent associations between younger age and spending power, low income and spending power, money problems, and mental health problems for older respondents are all directly associated with 'running out of food'. Other direct effects include not having private health insurance, having a low income, discretional income and mental health. Mental health also has an indirect effect mediated by high psychological distress, with the score measured by the K10 scale. 
Respondents who are younger or who have very low incomes are more than five times as likely to report 'running out of food' compared with older age respondents and those with higher incomes. Respondents with money problems, low discretional income, and those with both low income and low discretional income are more than three times as likely to report 'running out of food' compared with respondents who don't have money problems and higher income as well as higher discretional spending power.

\subsection{Adjustment for Covariates and Indicators of Hypothetical Causality}

Using iterative propensity score weighted analyses, three areas of the path were tested for hypothetical causality with regard to food insecurity: Having a low annual household income, an inadequate perceived discretional income and obesity. Additionally, two areas were tested for possible causality due to food insecurity: Eating fast food more than twice a week and not eating any vegetables. Table 3 shows the results for the link between food insecurity and having an annual household income of up to AUD $\$ 20,000$, being able to save versus other discretional income categories and being obese versus not.

Table 3. Estimate of probability of food insecurity ('running out of food' and not being able to afford more) by income, discretional income and obesity, adjusted using propensity scores: Showing probable antecedent factors of 'running out of food', HWSS 2009-2013.

\begin{tabular}{|c|c|c|c|c|c|c|}
\hline $\begin{array}{l}\text { Outcome: 'Running out of Food' at Least Once in the } \\
\text { Previous Twelve Months }\end{array}$ & Coef. & $95 \%$ & CI & $\begin{array}{l}\text { Robust } \\
\text { Std. Err }\end{array}$ & $\mathbf{Z}$ & $p$ \\
\hline \multicolumn{7}{|l|}{ Annual household income } \\
\hline Average effect when income $<\$ 20,000$ & 0.038 & 0.013 & 0.063 & 0.013 & 3.02 & 0.003 \\
\hline Probability if income is $>\$ 20,000$ & 0.028 & 0.025 & 0.03 & 0.001 & 19.33 & $<0.001$ \\
\hline \multicolumn{7}{|l|}{ Discretional income } \\
\hline Difference between spend left over vs. able to save & 0.023 & 0.014 & 0.033 & 0.005 & 4.85 & $<0.001$ \\
\hline Difference between just enough vs. able to save & 0.056 & 0.046 & 0.067 & 0.005 & 10.48 & $<0.001$ \\
\hline Difference between not enough vs. able to save & 0.066 & 0.048 & 0.083 & 0.009 & 7.38 & $<0.001$ \\
\hline Average probability of outcome for those able to save & 0.012 & 0.009 & 0.014 & 0.001 & 9.05 & $<0.001$ \\
\hline \multicolumn{7}{|l|}{ Obesity } \\
\hline Difference in probability when obese & 0.008 & 0.003 & 0.013 & 0.003 & 3.15 & 0.002 \\
\hline Average probability of outcome if not obese & 0.029 & 0.026 & 0.032 & 0.002 & 17.88 & $<0.001$ \\
\hline
\end{tabular}
vs $=$ versus.

The first line of Table 3 shows the difference in the probability of 'running out of food' for the population with low income compared with those with a higher income. The second line of the table shows the probability for a reference higher income group 'running out of food'. The overall probability of 'running out of food' for the low income group is the sum of the two coefficients (e.g., $0.038+0.028=0.066$ ). The next lines of Table 3 show the difference between the population and the reference category(ies) with which they are being compared for the independent variables: Perceived discretional income and obesity. The Supplementary Table S1 shows the full model for incomes above and below $\$ 20,000$.

Table 4 shows the difference between the population and the reference category(ies) with which they are being compared for eating fast food three or more times a week and not eating vegetables. Eating fast food three or more times a week precedes eating no vegetables (as assessed using BIC in the path analysis). 
Table 4. Estimate of probability of eating fast food more than twice a week and eating no vegetables by 'running out of food', adjusted using propensity scores: Showing probable outcomes of 'running out of food', HWSS 2009-2013.

\begin{tabular}{|c|c|c|c|c|c|c|}
\hline Outcome: & Coef. & $95 \%$ & CI & $\begin{array}{l}\text { Robust } \\
\text { Std. Err }\end{array}$ & $\mathbf{Z}$ & $p$ \\
\hline \multicolumn{7}{|l|}{ Eats fast food more than three times a week } \\
\hline Difference in probability of 'running out of food' vs. not & -0.007 & -0.013 & -0.0002 & 20.003 & -2.03 & 0.042 \\
\hline Average probability of outcome when didn't run out & 0.019 & $<0.001$ & 0.017 & 0.001 & 17.83 & $<0.001$ \\
\hline \multicolumn{7}{|l|}{ Eats no vegetables } \\
\hline Difference in probability of fast food $>2$ times weekly & 0.029 & 0.007 & 0.051 & 0.011 & 2.61 & 0.009 \\
\hline Average probability of FI when fast food $<3$ times weekly & 0.006 & 0.005 & 0.007 & 0.001 & 10.32 & $<0.001$ \\
\hline
\end{tabular}

\section{Discussion}

This analysis using a population-based survey resulted in the description of a plausible and quantified pathway to food insecurity, as well as measurement of its dietary impacts. The findings support the hypothesis that food insecurity, measured by whether or not a household ran out of food in the last year, appears to more strongly precede the poor diet indicators of eating fast food three or more times a week and eating no vegetables. While this hypothesis has been proposed previously [51], this proof-of-concept study is the first to quantify both the relative importance of the factors within the feedback loop to food insecurity and the complex nature of the factors leading to it.

The odds of 'running out of food' were higher for younger adults, those without tertiary education and Aboriginal people (odds ratios of 5.53, 2.15 and 2.3 respectively). These findings are consistent with the findings of the Australian national dietary survey which found that the prevalence of food insecurity was higher in Aboriginal populations compared to non-Indigenous Australians (22\% compared to 3.7\%) [52]. A UK study of 10,452 adults found that different socioeconomic indicators predicted dietary intake, for example, economic access to food, educational attainment and age were related to fruit and vegetable intake and diet costs [53]. The study also showed that dietary costs were not equally important in the causal pathway between socioeconomic position, suggesting that health and diet may be a factor when allocating funding for food [53].

The risk of running out of money for food has been associated with one-off financial stressors such as medical or other expenses due to unexpected events [54] and the price of food has been shown to contribute to food stress among low income families [55]. This current research highlights many other interrelated and potentially changeable factors. Saving ability, at any income level, appears to protect against food insecurity. Financial over-commitment is particularly relevant during times of economic downturn, as has occurred in Western Australia over recent years. The financial stress of housing costs may contribute to food insecurity as people can no longer afford their mortgage or rent, leading to money for food, a discretionary expense, potentially being sacrificed and instead put towards covering housing costs.

Attitudes toward income inequality and how poor people manage their money and cope in stressful situations are underpinned by cultural beliefs, related to blame, plight and privilege [56]. Although most Canadians were willing to accept differences in income related health inequalities such as food insecurity, they were less willing to attribute health inequalities to differences in personal health practices and coping skills [56]. The current study found increased odds of smoking, eating fast food and obesity associated with running out of money to buy food, independent of income level. Similar associations with food insecurity, perceived financial difficulty, smoking, lower fruit and vegetable intake and higher discretionary food intake were found in a representative sample of French households [57].

There are significant associations with not having private health insurance and feeling a lack of control over one's own health, both of which have adjusted odds ratios of 1.9. There is also an increased likelihood of food insecurity associated with social, mental and physical disadvantage as 
noted in other studies [58]. The number of factors on the path support the notion of deprivation amplification [59]. The results also show that quantification of the degree and direction of effects associated with food insecurity is possible. This quantification lends support to the concept that there may be causality between some of the variables on the path.

According to the theory underlying propensity score methodology as developed by Rosenbaum and Rubin [60], adjustment for propensity scoring removes the influence of confounding by multiple covariates and provides plausible evidence for causation for cross-sectional studies, even though one cannot ascribe any statistical significance to the findings [61]. The results from this current study suggest evidence of a hypothetical causal relationship within the path for the variables presented. The direction of effect is the relative strength of the association, so for example, while obesity may follow FI, it more strongly precedes it. The same applies to eating no vegetables and fast food consumption, which also precede but more strongly follow FI as shown in the path diagram. This is one possible path to FI which provides opportunities to investigate the mechanisms underlying its effects and the mediation illustrated in the path diagram. Other paths to FI can further investigate latent effects such as dietary eating patterns [10]. Unhealthy eating patterns are associated with similar sociodemographics found in the FI pathway of this study [62].

There is value for policy decision makers in quantifying both the relative importance of a range of associations with food insecurity and constructing a path to food insecurity. The path diagram uses a population dataset with enough statistical power to allow for a subsequent investigation of possible causal links, highlighting the need to address the determinants of food insecurity as well as considering the consequences. The complex nature of the path also adds weight to the need for inter-sectoral collaborations to address the various determinants of food security. The results from the path diagram support the need for a system level policy to address this $[63,64]$. For example, obesity, which in the path diagram more strongly precedes FI has been shown also to follow it [62,65], suggesting the need for a policy that addresses both obesity as well as FI in tandem rather than as a separate policy for each.

The strength of this analysis is that the population survey and large sample size enabled the complex analysis to establish a proof-of-concept study to be undertaken. As with all survey data, there are limitations associated with this research, including some level of non-response and the self-reported nature of the data. The use of sample design weights incorporated in iterative proportional fitting (IFP), also known as 'raking', allowed for adjustment of over and under representation of age, gender and area of residence within the sample. This weighting was also incorporated into the multivariable regression models. The one question measure of food insecurity, based on 'running out of food' and not being able to afford more, does not measure the extent and experience of food insecurity, nor did the self-reported brief diet questions measure actual dietary intake. However, that was not the purpose of this investigation, which was to explore the complex mix of influences leading to FI. A further limitation was the omission of questions relating to attitudinal and lifestyle behaviours which would have allowed for the creation of a model that included these modifiable attributes.

\section{Conclusions}

The findings support evidence that decisions about food insecurity are complex and interactive, with a variety of factors contributing to the issue. While the single measure of FI cannot be considered adequate to fully estimate the prevalence of FI, the proof-of-concept using this single measure showed expected associations and quantified the effects of 'running out of food' over a range of determinants, such as income and physical and mental wellbeing. The path diagram presented suggests that a wider approach to bringing about change in access and use of food needs to be considered. The findings highlight the need to focus policy effort on mitigating the social determinants of food insecurity and the potential complexity of the pathways to food insecurity. This requires a system approach to policy development for FI and we could encourage policy makers and researchers to use this methodology to explore and quantify the complex relationships leading to food insecurity. 
Supplementary Materials: The following are available online at http:/ /www.mdpi.com/1660-4601/15/12/2620/s1, Table S1: Illustrating the full model of propensity scoring for incomes above and below $\$ 20,000$.

Author Contributions: A.D. was involved in the conception and design of the HWSS; A.D. and C.P. were involved in the conception and design of the NMSS; A.D. and M.P. conceived the approach and analyzed the data; A.D. wrote the first draft of the paper; A.D., C.P., D.K., M.C., C.B., M.P. reviewed and agreed with final drafts of the paper.

Funding: This research was funded by Healthway, the Western Australian Health Promotion Foundation (Grant number 19986).

Acknowledgments: The Department of Health, Western Australia owns, conducts and funds the Health and Wellbeing Surveillance System (HWSS). The authors are grateful for the ongoing monitoring of nutrition relating attitudes and behaviours and encourage ongoing execution of the survey. Healthway, the Western Australian Health Promotion Foundation, funded the Food Law, Policy and Communications to Improve Public Health Project (Grant 19986) to assist the translation of research into practice. The funder had no role in study design, data collection and analysis, decision to publish, or preparation of the manuscript. All sources of funding of the study should be disclosed. A.D. undertook this work as part of her Doctor of Philosophy and received a Healthway Health Promotion Research Scholarship (23342) part of which is being used to support publication.

Conflicts of Interest: The authors declare no conflict of interest. A.D. and C.P. worked for the Department of Health, Western Australia. The founding sponsors had no role in the design of the study; in the analyses or interpretation of data; in the writing of the manuscript, and in the decision to publish the results.

\section{References}

1. Food and Agriculture Organization. Rome Declaration on World Food Security and World Food Summit Plan of Action: World Food Summit 13-17 November; FAO: Rome, Italy, 1996.

2. Anderson, S.A. Core indicators of nutritional state for difficult-to-sample populations. J. Nutr. 1990, 120, 1555-1600. [CrossRef] [PubMed]

3. Riches, G. Food Bank Nations: Poverty, Corporate Charity and the Right to Food; Routledge: New York, NJ, USA, 2018.

4. Hanson, K.L.; Connor, L.M. Food insecurity and dietary quality in us adults and children: A systematic review. Am. J. Clin. Nutr. 2014, 100, 684-692. [CrossRef] [PubMed]

5. Jones, A.D.; Ngure, F.M.; Pelto, G.; Young, S.L. What are we assessing when we measure food security? A compendium and review of current metrics. Adv. Nutr. 2013, 4, 481-505. [CrossRef] [PubMed]

6. Robaina, K.A.; Martin, K.S. Food insecurity, poor diet quality, and obesity among food pantry participants in hartford, ct. J. Nutr. Educ. Behav. 2013, 45, 159-164. [CrossRef] [PubMed]

7. Dowler, E. Symposium on 'intervention policies for deprived households' policy initiatives to address low-income households' nutritional needs in the uk. Proc. Nutr. Soc. 2008, 67, 289-300. [CrossRef] [PubMed]

8. Mook, K.; Laraia, B.A.; Oddo, V.M.; Jones-Smith, J.C. Food security status and barriers to fruit and vegetable consumption in two economically deprived communities of oakland, california, 2013-2014. Prev. Chronic Dis. 2016, 13, E21. [CrossRef] [PubMed]

9. Tingay, R.S.; Tan, C.J.; Tan, N.C.; Tang, S.; Teoh, P.F.; Wong, R.; Gulliford, M.C. Food insecurity and low income in an english inner city. J. Public Health Med. 2003, 25, 156-159. [CrossRef] [PubMed]

10. Thornton, L.E.; Pearce, J.R.; Ball, K. Sociodemographic factors associated with healthy eating and food security in socio-economically disadvantaged groups in the uk and victoria, australia. Public Health Nutr. 2013, 17, 20-30. [CrossRef] [PubMed]

11. Metallinos-Katsaras, E.; Must, A.; Gorman, K. A longitudinal study of food insecurity on obesity in preschool children. J. Acad. Nutr. Diet. 2012, 112, 1949-1958. [CrossRef] [PubMed]

12. Larson, N.I.; Story, M.T. Food insecurity and weight status among u.S. Children and families: A review of the literature. Am. J. Prev. Med. 2011, 40, 166-173. [CrossRef] [PubMed]

13. Crawford, P.B.; Webb, K.L. Unraveling the paradox of concurrent food insecurity and obesity. Am. J. Prev. Med. 2011, 40, 274-275. [CrossRef] [PubMed]

14. Hernandez, D.C.; Marshall, A.; Mineo, C. Maternal depression mediates the association between intimate partner violence and food insecurity. J. Womens Health 2014, 23, 29-37. [CrossRef] [PubMed] 
15. Young, S.L.; Plenty, A.H.; Luwedde, F.A.; Natamba, B.K.; Natureeba, P.; Achan, J.; Mwesigwa, J.; Ruel, T.D.; Ades, V.; Osterbauer, B.; et al. Household food insecurity, maternal nutritional status, and infant feeding practices among hiv-infected ugandan women receiving combination antiretroviral therapy. Matern. Child Health J. 2014, 18, 2044-2053. [CrossRef] [PubMed]

16. Whitaker, R.C.; Phillips, S.M.; Orzol, S.M. Food insecurity and the risks of depression and anxiety in mothers and behavior problems in their preschool-aged children. Pediatrics 2006, 118, E859-E868. [CrossRef] [PubMed]

17. Melchior, M.; Chastang, J.F.; Falissard, B.; Galera, C.; Tremblay, R.E.; Cote, S.M.; Boivin, M. Food insecurity and children's mental health: A prospective birth cohort study. PLoS ONE 2012, 7, e52615. [CrossRef] [PubMed]

18. Muldoon, K.A.; Duff, P.K.; Fielden, S.; Anema, A. Food insufficiency is associated with psychiatric morbidity in a nationally representative study of mental illness among food insecure canadians. Soc. Psychiatry Psychiatr. Epidemiol. 2013, 48, 795-803. [CrossRef] [PubMed]

19. Pobutsky, A.M.; Baker, K.K.; Reyes-Salvail, F. Investigating measures of social context on 2 population-based health surveys, hawaii, 2010-2012. Prev. Chron. Dis. 2015, 12, E221.

20. Friel, S. Climate change, food insecurity and chronic diseases: Sustainable and healthy policy opportunities for australia. N. S. W. Public Health Bull. 2010, 21, 129-133. [CrossRef] [PubMed]

21. Ashe, L.M.; Sonnino, R. At the crossroads: New paradigms of food security, public health nutrition and school food. Public Health Nutr. 2013, 16, 1020-1027. [CrossRef] [PubMed]

22. Tarasuk, V. Implications of a Basic Income Guarantee for Household Food Insecurity. Northern Policy Institute, 2017. Available online: https:/ / proof.utoronto.ca/wp-content/uploads/2017/06/Paper-TarasukBIG-EN-17.06.13-1712.pdf (accessed on 22 November 2018).

23. Lang, T.; Barling, D.; Caraher, M. Food, social policy and the environment: Towards a new model. Soc. Policy Adm. 2001, 35, 538-558. [CrossRef]

24. Food and Agriculture Organisation. Declaration of the World Summit on Food Security 16-18 November; Food and Agriculture Organisation: Rome, Italiy, 2009.

25. Carletto, C.; Zezza, A.; Banerjee, R. Towards better measurement of household food security: Harmonizing indicators and the role of household surveys. Glob. Food Secur. 2013, 2, 30-40. [CrossRef]

26. Ecker, O.; Breisinger, C. The Food Security System: A New Conceptual Framework. International Food Policy Research Institute, 2012. Available online: http:/ / ebrary.ifpri.org/cdm/ref/collection/p15738coll2/ id/126837 (accessed on 22 November 2018).

27. Rideout, K.; Seed, B.; Ostry, A. Putting food on the public health table: Making food security relevant to regional health authorities. Can. J. Public Health 2006, 97, 233-236. [PubMed]

28. Bastian, A.; Coveney, J. Local evidenced-based policy options to improve food security in south australia: The use of local knowledge in policy development. Public Health Nutr. 2012, 15, 1497-1502. [CrossRef] [PubMed]

29. Bell, E. Research for Health Policy; Oxford University Press: Oxford, UK, 2009.

30. Caraher, M.; Coveney, J. Public health nutrition and food policy. Public Health Nutr. 2004, 7, 591-598. [CrossRef] [PubMed]

31. Booth, S.; Smith, A. Food security and poverty in australia-challenges for dietitians. Aust. J. Nutr. Diet. 2001, 58, 150-156.

32. Tarasuk, V. Health implications of food insecurity. Soc. Déterm. Health Can. Perspect. 2004, 187-200.

33. Dinour, L.M.; Bergen, D.; Yeh, M.-C. The food insecurity-obesity paradox: A review of the literature and the role food stamps may play. J. Am. Diet. Assoc. 2007, 107, 1952-1961. [CrossRef] [PubMed]

34. Franklin, B.; Jones, A.; Love, D.; Puckett, S.; Macklin, J.; White-Means, S. Exploring mediators of food insecurity and obesity: A review of recent literature. J. Commun. Health 2012, 37, 253-264. [CrossRef] [PubMed]

35. HLPE, Nutrition and Food Systems. A Report by the High Level Panel of Experts on Food Security and Nutrition of the Committee on World Food Security; HLPE: Rome, Italy, 2017.

36. Foley, W.; Ward, P.; Carter, P.; Coveney, J.; Tsourtos, G.; Taylor, A. An ecological analysis of factors associated with food insecurity in south australia, 2002-2007. Public Health Nutr. 2010, 13, 215-221. [CrossRef] [PubMed]

37. Quine, S.; Morrell, S. Food insecurity in community-dwelling older australians. Public Health Nutr. 2006, 9, 219-224. [CrossRef] [PubMed] 
38. Russell, J.; Flood, V.; Yeatman, H.; Mitchell, P. Prevalence and risk factors of food insecurity among a cohort of older australians. J. Nutr. Health Aging 2014, 18, 3-8. [CrossRef] [PubMed]

39. Kleve, S.; Davidson, Z.; Gearon, E.; Booth, S.; Palermo, C. Are low-to-middle-income households experiencing food insecurity in victoria, australia? An examination of the victorian population health survey, 2006-2009. Aust. J. Prim. Health 2017, 23, 249-256. [CrossRef] [PubMed]

40. Marques, E.S.; Reichenheim, M.E.; de Moraes, C.L.; Antunes, M.M.L.; Salles-Costa, R. Household food insecurity: A systematic review of the measuring instruments used in epidemiological studies. Public Health Nutr. 2015, 18, 877-892. [CrossRef] [PubMed]

41. McKechnie, R.; Turrell, G.; Giskes, K.; Gallegos, D. Single-item measure of food insecurity used in the national health survey may underestimate prevalence in australia. Aust. N. Z. J. Public Health 2018, 42, 389-395. [CrossRef] [PubMed]

42. Butcher, L.M.; O'Sullivan, T.A.; Ryan, M.M.; Lo, J.; Devine, A. Utilising a multi-item questionnaire to assess household food security in australia. Health Promot. J. Aust. 2018. [CrossRef] [PubMed]

43. Australian Bureau of Statistics. Socio-Economic Indexes for Areas (Seifa) 2011; Australian Bureau of Statistics: Canberra, Australia, 2013.

44. Hayes, A.J.; Kortt, M.A.; Clarke, P.M.; Brandrup, J.D. Estimating equations to correct self-reported height and weight: Implications for prevalence of overweight and obesity in australia. Aust. N. Z. J. Public Health 2008, 32, 542-545. [CrossRef] [PubMed]

45. Andrews, G.; Slade, T. Interpreting scores on the kessler psychological distress scale (k10). Aust. N. Z. J. Public Health 2001, 25, 494-497. [CrossRef] [PubMed]

46. Gill, T.K.; Price, K.; Dal Grande, E.; Daly, A.; Taylor, A.W. Feeling angry about current health status: Using a population survey to determine the association with demographic, health and social factors. BMC Public Health 2016, 16, 588. [CrossRef] [PubMed]

47. Burnham, K.P.; Anderson, D.R. Multimodel inference-understanding aic and bic in model selection. Sociol. Methods Res. 2004, 33, 261-304. [CrossRef]

48. Raftery, A.E. Bayesian model selection in social research. Sociol. Methodol. 1995, 25, 111-163. [CrossRef]

49. Little, R.J.; Rubin, D.B. Causal effects in clinical and epidemiological studies via potential outcomes: Concepts and analytical approaches. Annu. Rev. Public Health 2000, 21, 121-145. [CrossRef] [PubMed]

50. StataCorp. Stata Statistical Software: Release 13; StataCorp LP: College Station, TX, USA, 2013.

51. Ramsey, R.; Giskes, K.; Turrell, G.; Gallegos, D. Food insecurity among adults residing in disadvantaged urban areas: Potential health and dietary consequences. Public Health Nutr. 2012, 15, 227-237. [CrossRef] [PubMed]

52. Australian Bureau of Statistics. 4727.0.55.005-Australian Aboriginal and Torres Strait Islander Health Survey: Nutrition Results-Food and Nutrients, 2012-13; Australian Bureau of Statistics: Canberra, Australia, 2015.

53. Mackenbach, J.D.; Brage, S.; Forouhi, N.G.; Griffin, S.J.; Wareham, N.J.; Monsivais, P. Does the importance of dietary costs for fruit and vegetable intake vary by socioeconomic position? Br. J. Nutr. 2015, 114, 1464-1470. [CrossRef] [PubMed]

54. King, S.; Moffitt, A.; Bellamy, J.; Carter, S.; McDowell, C.; Mollenhauer, J. When there not enough to eat: A national study of food insecurity among emergency relief clients. State Family Report 2012, 2, 137-161. [CrossRef]

55. Landrigan, T.J.; Kerr, D.A.; Dhaliwal, S.S.; Savage, V.; Pollard, C.M. Removing the australian tax exemption on healthy food adds food stress to families vulnerable to poor nutrition. Aust. N. Z. J. Public Health 2017, 41, 591-597. [CrossRef] [PubMed]

56. Lofters, A.; Slater, M.; Kirst, M.; Shankardass, K.; Quinonez, C. How do people attribute income-related inequalities in health? A cross-sectional study in ontario, canada. PLoS ONE 2014, 9, e85286. [CrossRef] [PubMed]

57. Bocquier, A.; Vieux, F.; Lioret, S.; Dubuisson, C.; Caillavet, F.; Darmon, N. Socio-economic characteristics, living conditions and diet quality are associated with food insecurity in france. Public Health Nutr. 2015, 18, 2952-2961. [CrossRef] [PubMed]

58. Stuff, J.E.; Casey, P.H.; Szeto, K.L.; Gossett, J.M.; Robbins, J.M.; Simpson, P.M.; Connell, C.; Bogle, M.L. Household food insecurity is associated with adult health status. J. Nutr. 2004, 134, 2330-2335. [CrossRef] [PubMed] 
59. Macintyre, S. Deprivation amplification revisited; or, is it always true that poorer places have poorer access to resources for healthy diets and physical activity? Int. J. Behav. Nutr. Phys. Activ. 2007, 4, 32. [CrossRef]

60. Rosenbaum, P.R.; Rubin, D.B. The central role of the propensity score in observational studies for causal effects. Biometrika 1983, 70, 41-55. [CrossRef]

61. Habicht, J.P.; Victora, C.G.; Vaughan, J.P. Evaluation designs for adequacy, plausibility and probability of public health programme performance and impact. Int. J. Epidemiol. 1999, 28, 10-18. [CrossRef] [PubMed]

62. Daly, A.; Pollard, C.M.; Kerr, D.A.; Binns, C.W.; Phillips, M. Using short dietary questions to develop indicators of dietary behaviour for use in surveys exploring attitudinal and/or behavioural aspects of dietary choices. Nutrients 2015, 7, 6330-6345. [CrossRef] [PubMed]

63. Caraher, M.; Furey, S. The Economics of Emergency Food Aid Provision: A Financial, Social and Cultural Perspective; Palgrave Macmillan: Basingstoke, UK, 2018.

64. Steiner, J.F.; Stenmark, S.H.; Sterrett, A.T.; Paolino, A.R.; Stiefel, M.; Gozansky, W.S.; Zeng, C. Food insecurity in older adults in an integrated health care system. J. Am. Geriat. Soc. 2018, 66, 1017-1024. [CrossRef] [PubMed]

65. Kaiser, M.L.; Cafer, A. Understanding high incidence of severe obesity and very low food security in food pantry clients: Implications for social work. Soc. Work Public Health 2018, 33, 125-139. [CrossRef] [PubMed]

(C) 2018 by the authors. Licensee MDPI, Basel, Switzerland. This article is an open access article distributed under the terms and conditions of the Creative Commons Attribution (CC BY) license (http:/ / creativecommons.org/licenses/by/4.0/). 